\section{Good for 'You': Generic and Individual Healthy Eating Advice in Family Mealtimes}

\author{
SALLY WIGGINS \\ Nottingham Trent University, UK
}

SALLY WIGGINS has recently moved to the Psychology department, University of Strathclyde. Prior to this, she was a lecturer at Nottingham Trent University, and completed her $\mathrm{PhD}$ at Loughborough University in 2002. Her main research interests are food and eating practices, weight management and identity construction in everyday interaction.

ACKNOWLEDGEMENTS. An earlier version of this article was presented at the 2nd International Conference on Reconstructing Health Psychology: Critical and Qualitative Approaches, Aston, August 2001. I am grateful to Jonathan Potter for discussions on this issue, and for his substantive part in developing this research project. I would also like to thank Kerry Chamberlain and two anonymous reviewers for their helpful comments on an earlier version of this article.

COMPETING INTERESTS: None declared.

ADDRESS. Correspondence should be directed to: DR SALLY WIGGins, Department of Psychology, Strathclyde University, Graham Hills Building, 40 George Street, Glasgow, G1 1QE, Scotland. [email: sally.wiggins@strath.ac.uk]
Journal of Health Psychology Copyright () 2004 SAGE Publications London, Thousand Oaks and New Delhi, www.sagepublications.com Vol 9(4) 535-548

DOI: $10.1177 / 1359105304044037$

\section{Abstract}

Healthy eating is one of the main concerns for health organizations in the UK, and has been widely promoted in recent decades. Yet despite the amount of nutritional information available, levels of obesity, heart disease and other food-related diseases remain high. Existing research in this area often uses individual accounts of consumption to examine the reasons why people may not be eating 'healthily'. An alternative way to approach this issue is to examine how healthy eating advice is constructed and used in everyday interaction. This research uses tape-recorded family mealtimes to examine instances where nutritional advice is embedded and managed in conversational activities. A distinction between generic and individually focused healthy eating talk is illustrated, and the implications for further research are discussed.

\section{Keywords}

construction, discursive psychology, eating practices, food talk, health 
HEALTHY eating is an increasingly significant issue in western societies concerned with longevity and the health costs of heart disease, obesity, osteoporosis and other problems that are strongly affected by diet (Chamberlain, 2002; Conrad, 1994; Eldridge \& Murcott, 2000; Keane, 1997; Marks, Murray, Evans, \& Willig, 2000). Despite this, the large amount of nutritional and dietary information about healthy eating is still often markedly at odds with what is actually eaten (Dube \& Cantin, 2000; Young, 2002). This study aims to contribute to our understanding of how nutritional information is used in practice. It focuses on everyday eating practices, and in doing so examines the ways in which people construct, manage and undermine healthy eating talk. ${ }^{1}$ Before moving on to the theoretical principles behind this study, I shall first outline current developments in research on healthy eating.

\section{Changing attitudes towards healthy food}

Psychological research on healthy eating has frequently placed an emphasis on individual attitudes and intentions to eat particular foods (Santich, 1994). Such research often aims to determine which food preferences exist and how these affect eating behaviour (e.g. Cantin \& Dube, 1999; Sparks, Conner, James, Shepherd, \& Povey, 2001), and thus how these can be changed toward healthier diets. The methods used to study these attitudes and intentions primarily draw upon questionnaires or interviews, and a range of models to explain food choice (Bennett \& Hodgson, 1992). For example, participants may be asked about their past, current or intentional eating habits. These data are then often used to make recommendations about how eating behaviours could be changed.

A key finding from this body of research is that while people may be aware of nutritional advice, this knowledge is rarely put into practice (Coveney, 1999; Croll, Neumark-Sztainer, \& Story, 2001; McBean \& Miller, 1999; Young, 2002). Concerns have been raised that health education messages do not fit in with lay models of health (Ikeda, 1999; Lupton \& Chapman, 1995). Consequently, there has also been an increasing focus on the meanings that people ascribe to healthy eating, within psychological and sociological research (Dixey, 1998; Rawson, 1992; Winter Falk, Sobal, Bisogni, Connors, \& Devine, 2001). The aim with this type of research is thus to determine how people perceive healthy eating and how important it is for them. Interviews and focus groups are predominantly used to elicit these lay meanings, and the results are often fed back into nutrition education research (Hill, Casswell, Maskill, Jones, \& Wyllie, 1998; Wardle, Parmenter, \& Waller, 2000).

Underlying both of these areas of research is a concern with how nutrition and healthy eating is promoted, and how this is understood and put into practice by consumers. Health education campaigns are often focused on the nutrients or chemicals within foods that have been linked with health problems (Chamberlain, 2002; Marks et al., 2000). As David Marks and his colleagues have noted, 'dietary guidelines are usually formulated in terms of nutrients. Consumers buy and eat foods and so they need to be able to translate recommendations about nutrients into how best to purchase foods' (Marks et al., 2000, p. 142, emphases in original). There seems to be a disparity, then, between how nutrition information is presented, and how it is managed by consumers.

\section{Feeding back into practice}

The majority of research on healthy eatingwhether psychological or sociological-is based on written or verbal accounts of eating habits. A problem arises when these accounts are used instead of an examination of how people actually eat in practice. Yet this appears to be the case. Claims are being made about the gap between healthy eating knowledge and practice without studying how this knowledge is managed or used in practice.

Other problems result from the focus on accounts of eating rather than practices. For example, the use of interviews or questionnaires sets the agenda for the kinds of responses that people can provide (Potter, 1997). The issue of healthy eating is raised by the researcher and taken out of the context of the eating environment. Being asked about eating habits within an interview or questionnaire encourages participants to generalize their views or beliefs. They 
are rarely asked to focus on specific occasions, and thus the emphasis is on overarching or 'typical' views. The problem here is that these generalized responses are further removed from the particular foods and particular situations in which people eat.

A more troublesome issue here is that current research fails to examine how people translate information about nutrients into the consumption of food. Moreover, this assumes that-as noted in the above-mentioned literaturepeople work with a nutritional model of eating. It may be the case that healthy eating advice is reconstructed by people in their own terms, and that this is then used in the course of choosing or eating food. We therefore need to examine the ways people manage healthy eating, before we can make any further claims about how people are failing to put nutritional advice into practice.

\section{A discursive psychological approach to eating}

To address these problems, we need an approach that enables us to examine everyday situations in which people 'do' healthy eating, for example when shopping for foods, or preparing and eating meals. As noted earlier, most psychological research uses questionnaires, interviews or focus groups to collect data, though this produces either retrospective or prospective accounts of eating practices. By contrast, the current study uses discursive psychology (henceforth, DP; Potter \& Edwards, 2001a) to examine how healthy and, equally often, unhealthy eating is bound up with other activities and topics in interaction. This brings the focus back onto practices and how nutritional information or advice may be incorporated into everyday situations.

Discursive psychology is a theoretical and methodological approach concerned with the way discourse is oriented to action and the way psychological concerns are managed interactionally (Edwards, 1997; Horton-Salway, 2001a, 2001b). Applying this approach to food talk has helped understand the way people construct complaints and compliments, and give assessments, opinions and justifications (Wiggins, 2001). Food and eating talk is not just talk about food; it is also bound up with social relations and the practicalities of daily life
(Wiggins, 2002; Wiggins, Potter, \& Wildsmith, 2001). DP also draws on analyses of rhetoric (Billig, 1992) that show the way particular dilemmas and commonplaces-such as those associated with healthy eating — are managed in interaction.

The concern here is thus to examine how healthy eating is constructed, managed and used in interaction. It also involves a reconsideration of what we define as 'healthy food'. Often this relies on nutrition guidelines, such as those provided by the British Nutrition Foundation, or the governmental Department of Health. Instead, we can focus on everyday constructions of healthy eating as being thoroughly social and localized definitions. These are more important in terms of how people account for or justify their eating habits, and are more likely to be used to guide food choice.

\section{Aims of the research}

This study is designed to contribute to health promotion research by explicating the interactional context of healthy eating. I examine how healthy eating is constructed, managed and undermined in the context of everyday family mealtimes, as an example of how healthy eating is analysable in action. In particular, this study focuses on how participants orient to health claims about what food contains or consists of, such as vitamins, sugar and so on. The research should be considered as a starting point for further work, highlighting initial findings and providing examples of how healthy eating talk may be constructed in daily interaction.

\section{Method}

\section{Materials and participants}

The data for this study are taken from a corpus of tape-recorded family mealtime interaction. Ten families were recruited via personal contacts, using the criteria that they contained at least one child, and ate together on a regular basis. This ensured that the taped interactions would not require a change in household routines, and that there would more likely be socialization into food and eating habits. Pilot research indicated that families with younger children were also more likely to eat together frequently than were non-family adult groups. 
The families were located within a limited geographical spread in the north and midlands areas of England, though as is typical for a DP study, the focus is on examples of talk rather than on particular characteristics of the individuals themselves. The families self-recorded their meals using audio equipment (supplied by the researcher) as regularly as possible, over a period of between 4 and 20 weeks. The total data corpus consists of 86 mealtimes, spanning 40 hours of recorded conversation. All names and identifying details have been anonymized.

\section{Analytic procedure}

The audio-tapes were initially transcribed to first-pass (words only) standard. Then all sections that included talk relevant to food or eating were fully transcribed. The transcription system used was that developed by Gail Jefferson (Jefferson, 1984; see also Hutchby \& Wooffitt, 1998). This highlights features of speech delivery as well as emphases, intonation and sequential detail (see Appendix for a key to notation). Both the tapes and the transcript were then used during analysis, which involved collecting together instances of healthy eating talk. The criteria used were that the talk made direct or indirect reference to food/drink having positive or negative health implications. More specifically, there was a focus on talk in which the contents or constituent parts of foods were discussed.

A discursive psychological approach to the data was used in the analysis (Horton-Salway, 2001a; Potter \& Edwards, 2001a, 2001b). This approach focuses on the action orientation and rhetorical organization of discourse. The data examples were examined in terms of their construction, sequential placement and otherspeaker orientation. I was concerned with how healthy eating talk was managed in interaction, and how it was used or countered by alternative constructions. These observations could then be related back to current nutrition education practices and promotion policies. The following extracts were selected as they provide a clear and representative illustration of the analytic focus.

\section{Analysis and discussion}

The analysis focuses on how the content or nutritive value of food is constructed and

managed as a healthy eating concern. The extracts here demonstrate how health can be used as a means of justifying or accounting for eating food. However, this is also bound up with other accounts and activities in the interaction. Healthy eating talk cannot easily be separated from managing conversational turns, negotiating the content of family meals or relating to other family members, for example. It was also noted that talk about food and health was often directed at individuals or constructed as general advice. The analysis is therefore sub-divided into two sections to show this broad distinction more clearly, and to examine the implications of these differing constructions.

\section{General advice giving}

In this section, examples are provided to demonstrate how nutritional or healthy eating talk is constructed as generic, universal advice. Often this is associated with justifying the choice of a particular food at the family meal. What is good for everyone, therefore, is good to serve at a shared meal. In Extract 1, for example, the 'green bits' in the sausages are justified in terms of both their health benefits and the cost of the food. The participants here are Sandra, her children, Julie, Darren and Amy and Darren's friend, Matthew.

Extract 1: SKW/K2b-M7 (69-93)

1.

2. Julie:

3. Darren:

4.

5. Sandra:

6.

7. Sandra:

8.

9. Julie:

10. Sandra:

11.

12. Julie: what's in $\uparrow$ these [saus $\downarrow$ ages: then

[it's $\uparrow w e l l$

funny (0.4) it's

[well-

$[>$ I don't $<\downarrow$ know

sausage $\downarrow$ meat ${ }^{\circ} h^{\circ}{ }^{\circ}$

Tyeah but- (0.4) they've got gree: $n$ bits $>$ in $\downarrow$ 'em<

oh herbs:

herbs 
13. Sandra: $\rightarrow$ they're $\uparrow$ really good for you (0.4) 'erbs:

14.

(0.6) 'erbs are really ${ }^{\circ}$ good for you $^{\circ}$

15. Darren: 'e[rbs? hheh heh

16. Matthew: [' $\downarrow$ erbs (0.2) 'erbs:

17.

18. Sandra: >they were $\uparrow$ on offer $<$ at Sains $\downarrow$ bury's ${ }^{\circ}$ so you got- ${ }^{\circ}$

19. Darren: [wh(hh)at the 'erbs

20. Matthew: [heh heh

21.

22. Sandra: $>$ heh heh $<$ ['erb-

23. Matthew: [heh [heh heh heh

24. Amy: [we $\uparrow$ live on offers:

25.

$(10.0)$

There are a number of ways in which healthy eating talk is managed here. First, Julie points out the 'green bits' (line 9) in the sausages, and in doing so highlights the potentially unusual quality of the food. These are not just sausages, but sausages containing an unknown object(s). Note how Sandra responds by downplaying their significance, through an oh-prefaced response ('oh herbs', line 10), indicating that this is not a new or strange food after all (Heritage, 1998). The 'green bits' become 'herbs', and later 'erbs'. As such, their presence in the food is constructed as a familiar, rather than an unknown object. It is interesting to note then how Darren and Matthew take up this abbreviated expression ('erbs', lines 15, 16 and 19) as if the style of talking is some sort of joke or comical expression. The form of the expression, with the colloquial dropping of the ' $h$ ', serves to become an alternative source of interest and focus for the interaction.

The second way in which healthy eating talk is managed by the family members is through its construction as being 'good for you' (lines 13 and 14), a commonly used phrase in nutritional guidelines and media sources (Bennett \& Hodgson, 1992; Marks et al., 2000). Yet it is descriptively vague and fails (without further elaboration) to specify exactly how the food is 'good'. Often this vagueness may be followed by more specific characteristics, for example, that a food may contain particular benefits such as 'improving circulation' or 'maintaining healthy skin'. In this respect it may be associated with talk in which the constituent parts of foods are discussed. In the example above, it is the herbs or the 'green bits' in the sausages that Sandra constructs as the beneficiary part of the food. While this does not clarify how the herbs are 'really good for you', the lack of questioning by other speakers shows that this serves as a suitable account in this part of the interaction.

A final point about this extract is how the relevance of the food is discussed in terms of the price of sausages; as being 'on offer' at the shop where Sandra bought them (line 18). The choice of food is accounted for in terms of saving money. This is something that Amy attends to as a recurring theme in the family, that they 'live on offers' (line 24), significant particularly as there is a guest present at the meal (Matthew). Following on from the focus on the "erb' expression, the health value of the food is here downgraded further through not being the underlying reason for the choice of food at this meal. Being 'good for you', instead, is a consequential feature of the purchase. More importantly, it accounts not for why they were bought, but for the strange 'green bits' that may cause concern to the children at this mealtime.

The second extract also illustrates how healthy eating talk may be constructed as general advice and as justifying the provision of certain foods at the meal table. It is taken from near the beginning of a meal, when the family is discussing the gravy that has been served. This gravy has been home-made using juices from the meat and vegetables, rather than using reconstituted gravy granules.

\section{Extract 2: SKW/K2b-M8 (62-134)}

1.

2. Darren: taste:s alright

3. Sandra: $\uparrow \underline{m m m}$

4.

5. Ian: $\rightarrow$ it's gravy $>$ without the $<\underline{\text { E's: : }}$

6. 
7. Sandra: $\uparrow$ no (0.4) it's quite $\uparrow$ healthy that $\downarrow$ gra: vy

8.

9. Ian: this:

10.

11. Sandra:

no (0.4) gravy granules:

12.

13. Sandra: healthier than $\downarrow$ this

14. Ian: >is it<

15. Sandra: ${ }^{\circ} \underline{m m m}^{\circ}(0.2) \cos$ when you do slimming $\downarrow$ world they

16.

17. recommend you use granules (.) rather than,

18. Sandra: home made gravy

19.

20. Ian: ${ }^{\circ}$ oh right ${ }^{\circ}$

21.

22. Sandra: $\uparrow$ very low in fạ:t

23.

24. Ian: ${ }^{\circ} \mathrm{mm}^{\circ}$

25. Julie: $\rightarrow$ well it's just wa:ter and the $\uparrow$ granules $\uparrow$ isn't it

26. it's like-

27. Sandra: $>$ yeah [but $<$ it's-

28. Ian: [heh heh

29.

30. Sandra: no it- (0.4) your Dad's > thinking about $<(0.2)$

31. the artificial things: in it that32.

There are a number of interesting issues in this extract. Here, however, I shall focus on how the constituent parts of the gravy are constructed by the speakers as providing the health value in the food. Note how there are two different foods that are being contrasted here-the gravy that they are eating (home-made), and that which has been eaten on previous occasions (made from granules). The first point to note about this extract is how Ian's turn on line 5, 'it's gravy $>$ without the $<$ E's::', is treated by Sandra as a potential criticism of the other, reconstituted gravy. She displays an orientation to this turn as implying that the latter food has 'E's' in it (i.e. E-numbers, denoting artificial additives to the food), and that this makes it unhealthy. This is then confirmed by Ian's responses on lines 9 and 14.

What is going on here is a very subtle management of healthy eating talk, made all the more sensitive by the fact that the family are currently eating one of the items of food that is being discussed. This is no small point. Given that they are eating (and presumably, have eaten on previous occasions) gravy, Sandra may be held accountable for serving what is being constructed as unhealthy food. However, we can note that most of the talk focuses on the positive aspects of each food (being 'home made', line 18; 'very low in fat', line 22 , for example). No mention is made of the fat content, and so on, of the gravy that is being eaten compared to the gravy granules. By talking about the latter, the focus is taken away from any negative health qualities of the food they are eating. This highlights further the way in which the interactional context is important for understanding healthy eating talk.

The rest of the extract shows how the healthy eating talk is constructed in terms of food characteristics (being low in fat, made up of granules and water). These qualities are stated factually, with no hesitation or doubt, and indeed as advice coming from an external source (Potter, 1996; Wooffitt, 2001). The reference to 'slimming world' also adds an edge of authenticity to the talk; this is not just Sandra's opinion, but that of a recognized weight-loss organization. This makes the claims harder to refute for the others, unless they have experience of attending the same slimming club as Sandra. Given that she has said, 'when you do slimming world', (line 15), the implication is that this is not the case.

The final example for this section shows how the speakers manage generic advice alongside an individual's (Amy's) interest in a particular weight-loss diet. Prior to this extract, Amy raises the issue of a 'banana diet' that she had read about in a magazine. It is interesting to note how 
the rest of the family has something to say about this (including Darren and Julie). Prior to line 1, they begin discussing how the banana diet is not a feasible strategy. This is a rather lengthy extract, though it is included in detail here to show the development of the family discussion.

\section{Extract 3: SKW/K3b-M12 (471-662)}

1. Sandra: = you can [ $\uparrow$ actually $(0.4)$ could overdose on $=$

2. Ian

[well $\downarrow$ no: :

3. Sandra: $=$ potassium ${ }^{\circ}$ couldn't you $^{\circ}$

4.

5. Ian:

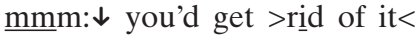
(0.4) your body keeps:

6.

(.) sodi $\downarrow$ um and (.) gets rid of the potassium

7. Darren: what's potassium $=$

8. Ian: = (so)

9. Darren: does it [make your he-

10. Julie: [(- - ) ((singing))

11. Ian: what is potassium [Darr $\uparrow$ en

12. Darren: [uhm (0.4) it's a gas

13. Ian:

14. wh- w:hat is potassium (.) what is the correct

15. Amy:

$\downarrow$ answer

16. Darren:

potassium permanganate

17.

18. Amy:

19. eh- (0.4) I'm not $\uparrow$ joking that is a sub $\downarrow$ stance

20. Darren: [y'know

[that is $(0.2)$ [yeah cos we used it in chemistry $=$

21. Sandra: [yeah I know

22. Ian: [it is (.) yeah

23. Darren: = the other d[ay ma-

24. Ian:
25. Sandra: used as an anti-[septic

26. Julie:

[duh:: (0.4) it's a (0.2) it's

27. an element thingy on-

28. Darren: what does ban $\uparrow$ anas: give you does it give you

29.

[ $\downarrow$ wind: or: :-

30. Ian: $\quad[<$ Potassium is a $\uparrow$ me:tal $>$

31. Sandra: $\rightarrow>$ well it $<(0.2)>$ it's $<$ it's $\uparrow$ high in fi $\downarrow$ bre: it's

[the perfect food [they $\downarrow$ say (.) don't ${ }^{\circ}$ they ${ }^{\circ}$

33. Julie: [^yeah::

\section{Darren: [heh heh}

The positive and negative health qualities of bananas form the basis for the discussion in this part of the interaction. What began as an interest in a particular dietary programme has shifted onto a more general discussion about bananas themselves. The advice giving is less focused on Amy as a result, and allows the rest of the family members to talk about the issue in a different way. It becomes more hypothetical, and therefore less accountable, if not tied to a specific person. Talk about 'your body' on line 5, for example, is not aimed at any one individual. This is a generic body, and thus abstracted from the current interaction. In a similar way, health promotion literature talks about the body and 'its' needs as a general-and thus unspecified and non-social-biological body.

The conversation also has the appearance of a pedagogical discussion on the nature of potassium. This highlights a second shift in focus towards the chemical elements in bananas, rather than on the more general health benefits noted in the discussion prior to this extract. For example, the fibre content is marked as being a positive feature on line 31. So, Amy is being dissuaded from following the 'banana diet' (in this and in the surrounding talk), through the subsequent biological reasons and justifications for this. Apparently factual information about the food is presented in a form that allows the children to participate in, and thus co-construct, the health benefits. There are clear links here to how nutritional guidelines are presented in 
health promotion leaflets and in product advertising. Both focus on the content of food and encourage the viewer/consumer to assess what they are eating.

This talk clearly constructs health as being reliant on specific factors in food-and consequently the food is less important than the nutritional content that they provide. This is further supported by the use of terms such as 'body ... gets rid of' (lines 5-6), 'give you' (line 28), which suggest an economical or computational model of inputs and outputs into the bodily system. What is concerning here is that no mention is made of other (primarily practical) issues around eating, such as the taste of food, availability, choice or the situations in which food is eaten.

From each of the extracts in this section, two key points can be highlighted. First, the healthy eating advice was constructed as a generic piece of advice, not aimed at any one individual. As a result, the conversation became more removed from the immediate situation as the discussion focused on a type of food (herbs, gravy, bananas) rather than a specific item of food. Second, the focus is on the qualities of the food (being low in fat, good for you and so on) rather than on the needs or habits of individuals. This constructs healthy eating advice as being more factual and objective, and separate from how the food is prepared, or the quantities in which it is consumed. The implications of this are that the advice does not easily relate to specific practices - in much the same way as nutritional information is thought to be presented to consumers.

\section{Focusing on the individual}

The second section of the analysis examines the ways in which healthy eating talk can be focused on an individual and their eating habits or consumption of a particular food. This kind of talk has greater practical implications, as it is more strongly tied to the eating practices at any one time. This is in contrast with the previous section, which showed how generic healthy eating talk is more easily abstracted from the current interaction, and thus less likely to have immediate consequences for the speakers involved.

In the first extract in this section, the family members (Mary, Dave and 21-year-old

daughter, Jo) are eating their evening meal. Also present is the family dog, which Dave has been talking to while sitting at the table. Here, it is Jo who initiates discussion about what her father should be eating. This illustrates how healthy eating talk need not be only passed on from parents to child(ren). The food in this instance is characterized as being different in some way through Dave's reference to it as 'rabbit food'.

\section{Extract 4: SKW/E2a-M2 (593-655)}

1.

2. Jo: $\rightarrow$

3. Dave:

4.

5.

6. Dave:

7.

8.

9. Dave:

$\underline{10 .}$

11. Jo: $\rightarrow$

12. Dave:

13.

14. Mary:

15.

16. Dave:

17. Mary:

18. Dave:

19.

20. Mary:

21. you haven't eaten your $\uparrow$ greens:

it's $\underline{\text { r:abbit }}{ }^{\circ}$ food $^{\circ}(0.6)$ I've ate en $\uparrow$ ou:gh of it

$\downarrow$ thanks:

I'd end up $\uparrow$ looking like a $\uparrow$ rabbit > wouldn't $\uparrow \mathrm{I}<$

((sound of clattering plates))

and then you'd be chasing me $\uparrow$ wouldn't you $=$

((as if spoken to dog))

$=$ it's got $\uparrow \underline{\text { vitamins in tho' }}$

I've $\uparrow$ ate a lot of $\downarrow$ it (0.6) 'ave the $\downarrow$ rest if

you [want it

[not 'alf of it

I $\downarrow$ 'aven't >I've had < more than 'alf of it $\uparrow$

$>{ }^{\circ}$ no you haven' $\mathrm{t}^{\circ}<$

I 'ave (0.6) (enough, yeah) ((comical, deep voice))

your daughter's maths: is getting $\downarrow$ better and

yours: is getting $\uparrow$ worse 
22.

23. Dave:

par个don ((in distance - leaves table/room))

24.

25. Mary: I said your dau:ghter's maths: is getting better

26.

and <yours is getting: $\uparrow$ worse $>$

27.

Jo uses the nutritional value of the food as a reason for why Dave should be eating his greens. Note how this is expressed: 'it's got 个vitamins in tho' (line 11). The shortened 'though' suggests that this is a reason to eat it despite it looking like rabbit food (line 3). Containing vitamins is thus constructed as being more important than other features of the food. It is also interesting to see how both Jo and Dave characterize the food as being stereotypically 'healthy', with the terms 'greens' (line 2) and 'rabbit food' (line 3). This is in contrast to saying 'cabbage' or 'broccoli', for example, and naming the specific food items. In doing so the interaction is oriented to the health aspects of the food, rather than other qualities (such as taste, familiar foods and so on). This is similar to the previous section, in which the food is characterized in a particular way. The difference here is that an item of food is being discussed in this way.

Another point of difference is that the focus is on Dave's particular avoidance of the food. The healthy eating talk-containing vitamins, for example-is thus directed at an individual and is of specific consequence. If Dave does not eat his greens, he will not be consuming the vitamins that he supposedly needs. Note how this is different from the previous extracts, in which the implications of eating or not eating food are more removed from the immediate interaction. Here the health 'information' is not being used as advice, so much as to hold Dave accountable for his mealtime practices.

The interaction above also shows how healthy eating talk is bound up with other aspects of sharing a meal. We see later in the extract how Dave accounts for himself by focusing on the amount of food eaten. This then becomes the subject for dispute (lines 14-26), and so the topic shifts away from the nutritional quality

per se. The speakers are also managing who has the right to tell another person to eat. Note how Jo is not heard in the latter part of the extract, and it is Mary who takes up the dispute over how much has been eaten. This is also negotiated through a subtle shift in focus; after disagreeing on the amounts eaten, Mary turns the conversation round to the ability to calculate correctly (lines 20-21, 25-26).

In Extract 5, Laura and her 11-year-old daughter, Beth, are sharing breakfast together. During this section of talk, Beth is eating her cereal while Laura is peeling herself an orange. Here we see how the eating habits of one individual (Beth) are constructed in relation to the current interaction.

\section{Extract 5: SKW/G5a-M23 (86-106)}

1.

2. Laura:

3.

4.

5. Beth:

6.

7. Laura:

8.

9. Laura: $\rightarrow$ you just like the: uhm (0.6) the $\uparrow$ chemical

10.

11. experiment called Sunny De个lig:ht

12. Laura: ${ }^{\circ}$ horrible stuff: ${ }^{\circ}$

13.

14. Laura: $>\underline{\mathrm{mm}}<$

15.

16. Laura: $\rightarrow{ }^{\circ}$ all that is is $\uparrow$ flavourings: ${ }^{\circ}$

17.

18. Laura: hh (.) have you done what she said (0.2) to 
19.

20. show that you have (0.4) mastered this level

you should complete $(0.4)$ [all five pages in to-

21. Beth:

$$
\text { : :s: : (0.4) well }
$$

In this extract the focus is on the drink 'Sunny Delight' as compared to other (fresh) orange juice. It is worth noting how Beth's tastes are constructed in this section of the conversation. That she 'just' likes (line 9, emphasis added) the 'chemical experiment called Sunny Delight' (lines 9-10) is important as it suggests that Beth has specific and inappropriate tastes. So it is not just that the food is unhealthy-being a "chemical experiment' and 'all ... flavourings' (line 16) - but that one of the speakers has a preference for it. This has implications for how healthy eating talk is to be managed. Here we see the unhealthiness and the individual preference being aligned. What this suggests, then, is that it is not just the drink that is being evaluated here; it is also Beth's tastes.

It is worth emphasizing this point for fear that it will otherwise be regarded as trivial or obvious. The drink (in this case, a manufactured form of orange juice) is constructed in rather negative terms, and Laura hints as to its damaging effects (chemicals, flavourings) as well as being 'horrible stuff' (line 12). This construction is also bound up with both the offering of the fresh orange juice and the reference to Beth's taste preferences. The implications of this are that Beth may simply treat it as a criticism of herself, rather than advice about the best kinds of orange juice to drink. Indeed, we can note how Beth says little at this point in the interaction, and Laura does not pursue the topic further. The conversation then moves onto a discussion of Beth's homework requirements for the remainder of the day. This further highlights the focus on Beth, rather than the drink.

Finally, we can note how the drink is constructed as being 'all ... flavourings' (line 16). This contrasts with previous extracts, in which the vitamins, trace elements and so on, are only part of the food or drink. If that were the case here, then the Sunny Delight may be redeemable in that it may have some beneficial qualities. Being entirely consisting of

flavourings, however, means that there is no advantage for health in its consumption. This is an issue that is raised in other extracts (see, for example, Extract 2 with the just water and the granules' turn on line 25), in which the health value of the food may also depend upon the other constituent parts. Potentially damaging or unhealthy aspects of food may be constructed and then minimized in light of the other nutritional values.

Extract 6 provides a clear example of this. Here, Laura and Beth are discussing whether it is 'better' to eat vegetables that have not been pre-washed. This follows Laura's account of serving sweets at a coffee morning after handling money. The discussion here demonstrates the fine line between talking about general 'advice' and relating this to individual consumption. Here, it is the talk about specific bodies and purchasing habits that bridges the gap.

\section{Extract 6: SKW/G1a-M2 (255-301)}

1.

2. Laura:

3.

4.

5.

6. Beth: and (you) can wash it

7. Laura: wash it (.) but it still leaves(0.2)

8. $\rightarrow$ cos you $\uparrow$ need the trac:e elements out of the-

$9 . \quad$ (0.4) so

$10 . \quad(1.0)$

11. Beth: yeah (0.4) whatever that means

12. Laura: $>\underline{m m m} \downarrow<$

$13 . \quad(1.4)$

14. Laura: ${ }^{\circ}$ things $^{\circ}$ like pot $\uparrow \underline{a s s i u m}$ and $>$ stuff like 
15.

that $\cos <$ you're not all made of:- (0.6) .hh

16. carbon hydrogen and oxygen (.) you $\uparrow$ do have

17. little bits: of other $\downarrow$ things in-

18.

19. Beth:

I'm made of wa:ter

20. Laura: that's hydrogen and $\uparrow$ oxygen (.) $\mathrm{H} 2$ 个证

21. Beth: ahh

22. Laura: and carbon

23.

Laura is accounting for two things here-the potential contamination of food at the coffee morning (dirt from the money), and her own practices of buying vegetables from a market stall. This is done through re-constructing the 'dirt' in terms of mineral content and the nutritional value of 'trace elements' (line 8). These are argued to be 'needed' (line 8), and a constituent part of one's body (lines 15-17). So, being healthy is constructed here as requiring the consumption of particular elements that are both found in soil, and found in the body. This is a strong rhetorical argument, as it constructs physiological needs that are beyond personal taste or choice. Hence, in serving and eating the potentially 'dirty' food, Laura is ensuring that she is acquiring the necessary nutrients and minerals that her body needs. This talk about personal choice in buying foods shows how the general 'advice' is being related to particular individual practices-healthy eating in action.

We can also note how Beth responds to the talk about the 'trace elements'. On line 11, she expresses agreement but also that this is unfamiliar talk, or something she is claiming to not know about. The conversation then takes on a pedagogic feel, with Laura telling Beth what her body is made of, and Beth responding with a simplified account ('I'm made of water', line 19). This is similar to the discussion in Extract 3 , in which the speakers all contribute to the construction of the health qualities of the food, through the coaxing of the adult members. What this shows is how healthy eating talk is often inseparable from other discursive-and in this case, familial-activities in interaction.

The extracts in this second section have shown a different way of managing healthy eating talk. Again, key points can be highlighted. First, the focus on individual habits or consumption suggests a more immediate and specific application of food nutrition. What is 'good for you' is localized and contextualized within a particular interaction, but is also more achievable as a result. That one individual should consume more greens, less 'Sunny Delight' and more 'dirty' vegetables is easier to manage when the food is already part of the diet or household storecupboard. Second, while there is still talk about what the food contains, this is linked to an individual's habits, and is thus more easily associated with the ways in which the food is eaten. For instance, it is not just that Beth drinks the chemical, flavoured drink, but that this is all she drinks. Quantity is as important here as quality.

\section{Conclusions}

This study has illustrated examples of healthy eating talk in everyday interaction. In particular, I noted a distinction between talk that is formulated as either generic consumption advice or directed toward individual practices. The latter form appears to have greater practical implications as it is tied to specific and situated eating habits. Some early conclusions can be made from this distinction. First, that healthy eating is not a unitary type of behaviour that can be separated out from other aspects of daily life; rather it is situated within practical and interactional contexts. This is evidenced in the way that healthy eating talk both constructs what is/not healthy and is bound up with other features of interaction (e.g. justifying meal choices to family members). This aspect of healthy eating is something that has not been stressed or sufficiently recognized by previous research, which tends to focus on people's views or attitudes towards particular foods. By doing so, it is treated as primarily an individual event, and thus as potentially distinct from what others may or may not do.

Second, and as a corollary of the first point, healthy eating advice may be managed through attending to particular, individual 
characteristics. That is, one person may warrant an account for not eating healthily by constructing, for example, their particular tastes, or physiological reactions to food. Moreover, what is understood as healthy eating is defined within a particular context. In the instances discussed earlier, the bodily needs of individuals—-such as those for potassium, or vitamins-were constructed as being generic requirements for consumption. Yet these do not take into account the specific needs of gendered, aged and/or differently constituted bodies. Hence, generic advice may be more easily dismissed as not applicable to individual circumstances.

Finally, the way in which healthy eating talk is oriented to shows more generally how people may manage healthy eating in practice. For instance, it may be regarded as advice about the foods that we should eat (and why we should eat them), or as part of the practical issues around food provision in the household. As we saw in Extract 1, Amy treats the inclusion of the herbs as being due to the family 'living on offers'; that the main reason Sandra bought the food was to save money rather than for health. What is 'good for you' is thus partly constructed here as being a convenient consequence of this purchase.

While this study examines a limited range of data, the distinction between generic and individually focused healthy eating advice warrants further study. For example, the data here suggest that it is easier to resist the generic advice as being too general, and thus not applicable to individual needs or circumstances. But how easily may one refute or disregard different forms of advice? We need to consider how advice is managed in interaction, particularly when on-the-spot judgements of food are being made. How do people construct and use advice when eating in different situations, or when purchasing or preparing food?

This study could be extended further by examining other forms of food and eating talk. The data used here were all taken from family mealtimes, so in a sense what we have here is 'mealtime talk', as opposed to 'food talk' per se. By looking at other instances of spontaneous food talk-in the supermarket, at work, in the pub and so on-we could build up a larger corpus of data from which to examine healthy eating talk. This could then be used to generate further understandings of how such practices are managed and embedded within other aspects of social life.

Further research could also contribute to the way in which healthy eating is constructed and promoted in the media. As noted in the introduction, much of the health promotion literature is often based on food groups (e.g. fats, carbohydrates) and associated eating practices (e.g. recommendations for daily calorific and fat intakes). Might these constructions be offering a particular version of health that does not allow for people easily to change or alter their current behaviour? For example, if we talk about bodily needs, or the components of foods, then we are bound up with a specific view of eating that is mainly physiological in nature, and leaves little room for the familial, social or cultural aspects of food practices. This construction may also be harder to realize in practice. As Williams (1995) has noted, for example, what counts as a 'portion' of various forms of fruit and vegetables is not so straightforward in everyday practice.

In summary, the research reported here offers an illustration of how a discursive approach can contribute to our understanding of healthy eating practices by examining everyday interaction around food. The distinction made here, between generic and individual healthy eating talk suggests that there are ways of managing 'advice', and that these are bound up with other interactional concerns. The analysis provides a more context-based approach to healthy eating, and indicates alternative ways in which we can make sense of the interaction between health promotion and actual eating practice.

\section{Appendix: Transcription notation}

The data were transcribed according to conventions laid out by Gail Jefferson (see Hutchby \& Wooffitt, 1998). These can be summarized as follows:

(.) A dot in a bracket indicates a pause of less than two-tenths of a second.

(0.2) Numbers in brackets refer to pauses in tenths of a second.

Colons indicate an extension of the preceeding vowel sound. The more 
colons there, the greater the extent of the stretching.

What Underlining indicates stress or emphasis in the speech.

$\uparrow \downarrow \quad$ Pointed arrows indicate a marked rising or falling in speech intonation.

[] Square brackets indicate the beginning and end of overlapping talk.

Well- A dash following a word indicates a cutoff sound at the end of the talk.

$>\quad$ 'Greater than' and 'less than' signs enclose speech which is noticeably faster than the surrounding talk. When the order is reversed $(<>)$ this indicates slower speech.

${ }^{\circ}$ heh ${ }^{\circ}$ Degree signs indicate talk that is noticeably quieter than the surrounding talk.

(()) Words in double brackets and italicized refer to transcriber's comments on features or non-verbal aspects of the interaction.

(so) Words in brackets indicate the transcriber's best estimate of unclear speech.

$=\quad$ Equal signs indicate continuous talk between speakers.

\section{Note}

1. Healthy eating talk is defined here as any talk that makes reference to food or eating habits that are good for you (or not), and/or bodily needs and the foods we should eat to satisfy these needs.

\section{References}

Bennett, P., \& Hodgson, R. (1992). Psychology and health promotion. In R. Burton \& G. MacDonald (Eds.), Health promotion: Disciplines and diversity (pp. 23-41). London: Routledge.

Billig, M. (1992). Talking of the Royal family. London: Routledge.

Cantin, I., \& Dube, L. (1999). Attitudinal moderation of correlation between food liking and consumption. Appetite, 32, 367-381.

Chamberlain, K. (2002). The medicalisation of food. Paper presented at Eat, drink and be merry conference, Amsterdam, The Netherlands, June.

Conrad, P. (1994). Wellness as virtue: Morality and the pursuit of health. Culture, medicine and psychiatry, 18, 385-401.

Coveney, J. (1999). The government of the table: Nutrition expertise and the social organisation of family food habits. In J. Germov \& L. Williams (Eds.), A sociology of food and nutrition: The social appetite (pp. 259-275). Oxford: Oxford University Press.

Croll, J. K., Neumark-Sztainer, D., \& Story, M. (2001). Healthy eating: What does it mean to adolescents? Journal of Nutrition Education, 33(4), 193-198.

Dixey, R. (1998). Healthy eating in schools, overweight and 'eating disorders': Are they connected? Educational Review, 50(1), 29-35.

Dube, L., \& Cantin, I. (2000). Promoting health or promoting pleasure? A contingency approach to the effect of informational and emotional appeals on food liking and consumption. Appetite, 35, 252-262.

Edwards, D. (1997). Discourse and cognition. London: Sage Publications.

Eldridge, J., \& Murcott, A. (2000). Adolescents' dietary habits and attitudes: Unpacking the problem of (parental) influence. Health, 4(1), 25-49.

Heritage, J. (1998). Oh-prefaced responses to inquiry. Language in Society, 27, 291-334.

Hill, L., Casswell, S., Maskill, C., Jones, S., \& Wyllie, A. (1998). Fruit and vegetables as adolescent food choices in New Zealand. Health Promotion International, 13(1), 55-65.

Horton-Salway, M. (2001a). The construction of M. E.: The discursive action model. In M. Wetherell, S. Taylor, \& S. J. Yates (Eds.), Discourse as data: A guide for analysis (pp. 147-188). London: Sage Publications.

Horton-Salway, M. (2001b). Narrative identities and the management of personal accountability in talk about ME: A discursive psychology approach to illness narrative. Journal of Health Psychology, 6(2), 247-259.

Hutchby, I., \& Wooffitt, R. (1998). Conversation analysis: Principles, practices and applications. Cambridge: Polity Press.

Ikeda, J. P. (1999). Culture, food and nutrition in increasingly culturally diverse societies. In J. Germov \& L. Williams (Eds.), A sociology of food and nutrition: The social appetite (pp. 149-168). Oxford: Oxford University Press.

Jefferson, G. (1984). Notes on a systematic deployment of the acknowledgement tokens 'yeah' and 'mm hm'. Papers in Linguistics, 17, 197-217.

Keane, A. (1997). Too hard to swallow? The palatability of healthy eating advice. In P. Caplan (Ed.), Food, health and identity (pp. 172-192). London: Routledge. 
Lupton, D., \& Chapman, S. (1995). 'A healthy lifestyle might be the death of you': Discourses on diet, cholesterol control and heart disease in the press and among the lay public. Sociology of Health and Illness, 17(4), 477-494.

Marks, D. F., Murray, M., Evans, B., \& Willig, C. (2000). Health psychology: Theory, practice and research. London: Sage Publications.

McBean, L. D., \& Miller, G. D. (1999). Enhancing the nutrition of America's youth. Journal of the American College of Nutrition, 18(6), 563-571.

Potter, J. (1996). Representing reality: Discourse, rhetoric and social construction. London: Sage Publications.

Potter, J. (1997). Discourse analysis as a way of analysing naturally occurring talk. In D. Silverman (Ed.), Qualitative research: theory, method and practice (pp. 144-160). London: Sage Publications.

Potter, J., \& Edwards, D. (2001a). Discursive social psychology. In W. P. Robinson \& H. Giles (Eds.), Handbook of language and social psychology (pp. 103-118). London: Wiley.

Potter, J., \& Edwards, D. (2001b). Sociolinguistics, cognitivsm and discursive psychology. In $\mathrm{N}$. Coupland, S. Sarangi, \& C. N. Candlin (Eds.), Sociolinguistics and social theory (pp. 88-103). London: Longman.

Rawson, D. (1992). The growth of health promotion theory and its rational reconstruction: Lessons from the philosophy of science. In R. Burton \& G. MacDonald (Eds.), Health promotion: Disciplines and diversity (pp. 202-224). London: Routledge.

Santich, B. (1994). Good for you: Beliefs about food and their relation to eating habits. Australian Journal of Nutrition and Dietetics, 51(2), 68-73.
Sparks, P., Conner, M., James, R., Shepherd, R., \& Povey, R. (2001). Ambivalence about health-related behaviours: An exploration in the domain of food choice. British Journal of Health Psychology, 6, 53-68.

Wardle, J., Parmenter, K., \& Waller, J. (2000). Nutrition knowledge and food intake. Appetite, 34, 269-275

Wiggins, S. (2001). Construction and action in food evaluation: Conversational data. Journal of Language and Social Psychology, 20(4), 445-463.

Wiggins, S. (2002). Eating your words: Constructing food and eating practices in mealtime conversation. Unpublished $\mathrm{PhD}$ Dissertation, Loughborough University, UK.

Wiggins, S., Potter, J., \& Wildsmith, A. (2001). Eating your words: Discursive psychology and the reconstruction of eating practices. Journal of Health Psychology, 6(1), 5-15.

Williams, C. (1995). Healthy eating: Clarifying advice about fruit and vegetables. British Medical Journal, 310, 1453-1455.

Winter Falk, L. W., Sobal, J., Bisogni, C. A., Connors, M., \& Devine, C. M. (2001). Managing healthy eating: Definitions, classifications and strategies. Health Education and Behaviour, 28(4), 425-439.

Wooffitt, R. (2001). Researching psychic practitioners: Conversation analysis. In M. Wetherell, S. Taylor, \& S. J. Yates (Eds.), Discourse as data: A guide for analysis (pp. 49-92). London: Sage Publications.

Young, I. (2002). Is healthy eating all about nutrition? Nutrition Bulletin, 27, 7-12. 